\title{
A SIMPLE SPECIFIC PRECIPITATION TEST FOR COW'S MILK
}

BY

\section{A. GNOSSPELIUS}

(From the Medical Department of the Children's Hospital, Gothenburg, Sweden, and from the Bacteriological Department, Sahlgren Hospital)

In recent years it has become a practical possibility to distinguish between various types of milk. The difficulty of providing children's hospitals with a sufficient supply of breast milk from wet-nurses has made it necessary to try to collect mother's milk either by voluntary contribution or by purchase. Thanks to successful collaboration with the local welfare centres, the Gothenburg Children's Hospital has succeeded in obtaining the required quantity of breast milk from mothers who have an ample supply of milk or from mothers who have already weaned their babies or are about to do so. In 1938, the Children's Hospital was thus able to purchase more than 300,000 c.c., three Swedish crowns per 1000 c.c. being paid for the milk. In the same way the welfare centres have succeeded in getting breast milk for special cases such as newborns and prematures, when for some reason the mother herself could not supply it. In several localities in Germany, France, Italy, and America, collection of mother's milk on a larger scale has been organized. In all these countries the necessity of controlling the contributed milk has arisen. A great deal of work has been devoted to trying to find a reliable method of detecting adulteration of breast milk by the addition of cow's milk. Both physicochemical and biological methods have been used. The methods and reactions used in differentiation between cow's milk and breast milk are briefly reviewed.

Umikoff, in 1896, showed that after adding ammonia and heating to $60^{\circ} \mathrm{C}$., breast milk turned a reddish-lilac colour, whilst cow's milk became yellow. According to Sieber the reaction depends on the lactose in combination with the citric acid present. The colour is influenced to a certain degree by the quantity of fat. Addition of cow's milk gives a weaker muddy grey colour, which clearly shows the difference when compared with pure breast milk from the same individual.

Tugendreich (1911) showed that on adding silver nitrate to breast milk and heating, the mixture assumed a brown or brownish-violet colour; whereas with cow's milk such a mixture remains colourless or has only a very faint colour. Commonly the reaction does not detect a moderate addition of cow's milk.

The neutral-red reaction of Moro (1912) is based on the different hydrogenion concentrations which exist in cow's milk and breast milk. The reaction

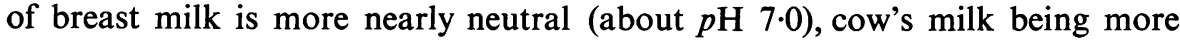


acid, with a $p \mathrm{H}$ between $6 \cdot 3$ and $6 \cdot 6$. Cow's milk and old sour breast milk, on the addition of neutral-red, give a red colour, whilst fresh breast milk turns yellow. In spite of an addition of 10 per cent. cow's milk the colour remains yellow or light yellow-red.

Bauer's (1913) nile-blue reaction is also a test which, like Moro's reaction, depends on the different hydrogen-ion concentrations. If a drop of 0.25 per cent. solution of nile-blue sulphate is added to a test-tube half-filled with ether which is then shaken and to which one to two c.c. milk are then added, the cow's milk after vigorous shaking sinks to the bottom and is blue-coloured, whilst fresh breast milk remains white. The colour disappears in a slightly acid aqueous solution, but persists in the ether in a neutral or alkaline reaction. Breast milk, when kept at room-temperature, becomes acid and gives a positive reaction. An addition of 25 to 30 per cent. of cow's milk to fresh breast milk is demonstrable by this reaction.

Edelstein (1921) used the relatively high lactose and low albumin content of breast milk to detect adulteration. From the tint which originates by a reduction of a copper salt solution by the lactose in the milk-serum, and by the amount of oxide of iron necessary for a quantitative precipitation of albumin, Edelstein was able to ascertain whether or not the mother's milk had been mixed with cow's milk or with water. An addition of 20 to 30 per cent. could thus be detected, but he did not consider this method always reliable.

Jacobi (1922) showed that on the addition of an equal quantity of concentrated sulphuric acid, breast milk turns brown, whilst cow's milk turns purple. Addition of cow's milk to the breast milk gives a darker brown colour. This difference in colour depends on a difference in the type of casein.

Zimmermann's method (1928) is based on the difference between the casein of breast milk and of cow's milk and the disparity in precipitation in the testtube due to this difference. The milk is mixed with decinormal sulphuric acid, diluted with distilled water. The cow's milk casein is precipitated as clots, which settle at the bottom as a sediment. According to Urbach (1938) the result is best read after forty-eight hours. Negative and positive control is necessary ; that is, an absolutely pure specimen of breast milk has to be compared with milk from the same individual adulterated 10 per cent.

Kapeller and Gottfried (1920) described a method which was based on the capacity for refracting light by the so-called acetic milk-serum. After adding a certain quantity of acetic acid, heating and filtering, serum from breast milk has a considerably higher light-refraction than that from cow's milk. From the degree of reduction in the refraction of light, it is possible to demonstrate an addition of 20 per cent. cow's milk or 10 per cent. water, but an absolutely reliable control from the same individual is necessary as a comparison.

Kayser (1927) pointed out that breast milk in ultra-violet light showed a bluish-violet fluorescence, and that cow's milk, on the contrary, gave a yellow one. Sometimes breast milk could also give a yellow fluorescence and later on Kayser $(1937 \mathrm{a}, \mathrm{b})$ has pointed out that eating liver produces exactly the same yellow fluorescence, probably depending on the presence of lactoflavin in the milk.

According to Grossfeld (1935) it would be possible to distinguish between breast milk and cow's milk by analysing the fat. The so-called butyric-acidfraction, which is an expression of the proportion of the lower fatty acids, butyric acid, and capric acid, is considerably less in the fat of breast milk than in the fat of buttermilk. The method could certainly be used, but is much too complicated to be practical.

The biological methods for distinguishing between the various kinds of milk are the precipitation reaction, the complement fixation reaction, and the anaphylactic test. From a practical point of view, the anaphylactic test is 
unavailable. Even the complement fixation test is too complicated, virtually requiring a special laboratory, but it is according to Bauer $(1913,1930)$ a distinct and specific reaction. Bordet, in 1899, was the first to show that if milk was injected into rabbits, precipitins were formed in the serum. It appeared that this reaction was not strictly specific, as it also gave positive reactions with the milk of nearly related animals. The test-serum from the cow also precipitates, for instance, goat's milk, though not in the same degree as the homologous milk. According to the researches of Hamburger, Schlossmann, Moro, and others, it is not only casein but also lactalbumin and lactglobulin which produce antibodies, though it is first and foremost the casein, which in the precipitation test gives the most evident reaction. The casein in itself is not a homogeneous product. Svedberg and Carpenter $(1930,1931)$ have been able to distinguish by the determination of the molecular weights three different fractions with molecular weights of 75,000 to 100,$000 ; 188,000$; and 375,000, which also remained distinct from a serological point of view (Carpenter and Hucker, 1930). The casein of breast milk and cow's milk differs in its chemical composition ; breast milk contains, amongst other things, a higher percentage of sulphur. There is no serological relationship, and a non-specific reaction is therefore not to be expected.

The precipitation reaction is, as is well known, carried out by carefully layering the solution which is to be examined, upon the specific precipitation serum. If positive, a slight precipitation disc forms at the junction of the solutions. In order to be able to distinguish this disc, which may be very small, both liquids must be as clear as possible. Although most of the fat is removed by vigorous centrifuging and the milk is highly diluted, it remains slightly milky. This makes the interpretation of the test impossible or very difficult. In these cases it is necessary to carry out the precipitation reaction more as an agglutination test. Dilutions of the milk to be examined are mixed with the specific serum. In a positive reaction the precipitate forms a sediment which sinks to the bottom of the test tube.

Jordanoff and Koschucharoff (1929) and Jordanoff (1932) in Sofia worked out a new serological method for differentiating different kinds of milk. This was the result of large scale attempts to distinguish between cow's, buffalo's, sheep's, or goat's milk. Most of the lactosera which they produced were nonspecific and often precipitated all types of milk. They only succeeded in getting pure specific sera after having begun to saturate the serum in vitro with the other kinds of milk. Such purified serum is called lactotest. They suggested that the reaction should be performed on a slide (as in a slide agglutination reaction or in blood grouping), and that undiluted milk and undiluted serum should be used. This precipitation reaction carried out on a slide is an excellent method, and is easy to execute and to interpret. Thanks to the fact that undiluted milk is used. the precipitin titre of the serum need not be high. It is of course desirable that the serum is sufficiently strong for an obvious and unmistakable reaction to be obtained. As the caseins in breast milk and cow's milk are not closely connected, the lactoserum need not be saturated and freed from non-specific components.

\section{Method}

The preparation of precipitin serum. Usually for the production of antibodies, rabbits are given an intravenous injection of gradually increasing doses of antigen every fourth or fifth day. At the beginning of my experiments. I adopted this procedure. The result was not successful. Following even the third milk-injection, some rabbits suffered from severe anaphylactic reaction 
and some actually died of anaphylactic shock. It was just those rabbits which showed an unusually good antibody-formation and consequently were especially suitable, which died of shock. By continuing my experiments and giving the rabbits a small desensitizing dose of $0 \cdot 1$ c.c. about half an hour before they got their regular injection, I succeeded in avoiding such mishaps. Recently I have adopted a different procedure. A certain number of rabbits were simultaneously injected five times intravenously with 5 c.c. milk on alternate days. The last injection was made with great care to avoid a possible anaphylactic shock. On the fourth day after the last injection the rabbits were bled and the sera generally showed a sufficient titre (1:20,000 or more). After having fasted one night, the rabbits were completely bled, in order to get the serum as clear and as fat-free as possible. As a preservative carbol was added to the serum to a concentration of 0.5 per cent.*

When testing the strength and suitability of a test serum, it is necessary, in addition to notifying the precipitation-titre, to do a preliminary slide precipitation test with breast milk containing varying amounts of cow's milk, for instance, 10 per cent., 5 per cent., 2 per cent., and 1 per cent. If there is a strong and rapid reaction with 10 per cent. and 5 per cent., and positive though weaker reactions with the lesser percentages of cow's milk, the serum should be considered suitable for the purpose.

Controls with pure breast milk must not, of course, give any reaction. The negative reactions like the weak positive ones, should be verified microscopically by slight magnification. When the serum gets old, the titre drops and before testing it should be controlled to see if it is still fit to be used. To keep the serum as long as possible, it must be put in an ice-box. Sometimes a deposit forms at the bottom of the bottle, and this has to be removed by centrifuging in order to avoid the risk of getting false positive reactions.

Performance of the test. A few cubic centimetres of the milk which has to be examined is centrifuged, and the fat which rises to the surface is removed. The small clots of fat which form when the milk is kept may simulate a positive reaction, at least to an inexperienced investigator. When small additions of cow's milk are to be detected this skimming of the milk is essential. Two or three platinum-loopfuls from the undiluted milk are put on the slide, after which one or two drops of test serum are added and stirred with a glass rod or the platinum needle. By slightly raising and rolling the slide, as in the examination of blood groups, the fluids are carefully mixed. When the reaction is positive, precipitates, which gather at the periphery of the drop, are formed immediately or within a few minutes. When the reaction is negative the fluid remains homogeneously turbid, and no flocculation occurs (fig. 1). Sometimes small lumps of fat are formed which appear in the middle of the test. With smaller additions of cow's milk the reaction may be difficult to interpret. Microscopically the flakes appear at the periphery (fig. 2), and can easily be distinguished from small masses of fat, if the fat of the milk has been almost all removed. Should there be too much fat in the milk the masses of fat adhere

* This method has successfully been used in other places, for instance, at the State Bacteriological Laboratory in Stockholm. 


\section{A SIMPLE SPECIFIC PRECIPITATION TEST FOR COW'S MILK 175}

to the small precipitates, and in that case it may be difficult even microscopically to distinguish them from normal small masses of fat.

Boiling the milk does not alter the result of the reaction. Casein is a thermostabile albumin. If breast milk mixed with cow's milk is kept in an ice-chest, the presence of cow's milk can be proved even after several days. On the contrary, if the milk is kept at room temperature the test cannot be performed

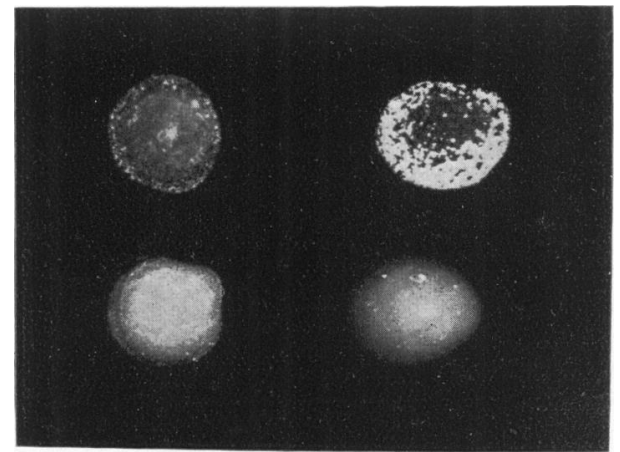

Fig. 1.-The slide precipitin test performed with cow's milk and with breast-milk containing 10 per cent., 3 per cent., and 0 per cent. of cow-milk.

as the milk goes sour. The casein separates and can no longer react with the specific serum. The diet of the mother has no effect on the reaction. Even when an increased quantity of cow's milk is taken, the method does not indicate

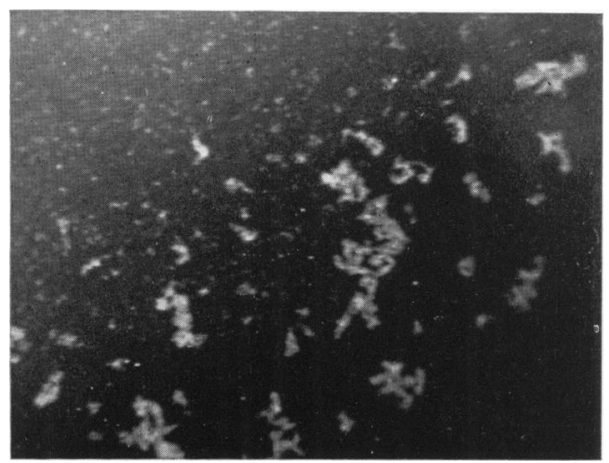

FiG. 2.-The reaction microscopically performed with 1 per cent. of cow's milk in breast-milk.

any adulteration of the breast milk (Urbach, 1938). This accords with Stuart's findings (1923) that albumin is not converted into milk and cannot be discovered in it, even after it has been taken in large amount.

\section{Conclusion}

This slide precipitation reaction is an excellent method for detecting admixtures of cow-milk with breast milk. Samples of breast milk from the same 
individual are not needed as a control. The test is specific and not influenced by the food consumed ; it is easily performed and gives a definite result in a few minutes. It is unquestionably better and more reliable than earlier known methods.

\section{REFERENCES}

Bauer, J. (1913). Die Methodik der biologischen Milchuntersuchung, Stuttgart.

- (1930). Handb. Milchwirtschaft, 1, 109.

Carpenter, D. C., and Hucker, G. J. (1930). J. infect. Dis., 47, 435.

Edelstein, F. (1921). Z. Kinderheilk., 30, 326.

Grossfeld, J. (1935). Z. Untersuch. Lebensmittel, 70, 459.

Handbuch der Lebensmittelchemie, (1936), 3.

Jacobi, W. (1922). Mschr. Kinderheilk., 23, 44.

Jordanoff, M. (1932). Z. Fleisch- u. Milchhyg., 42, 300.

, and Koschucharoff (1929). Jber. vet. Fak., Sofia, 16.

Kapeller, G., and Gottfried, A. (1920). Münch. med. Wschr., 67, 813.

Kayser, M. E. (1927). Ibid., 74, 2142.

- (1937a). Dtsch. med. Wschr., 63, 136.

(1937b). Loc. cit., 712.

- (1938a). Ibid., 64, 297.

- (1938b). Le lait, 18.

Moro, E. (1912). Münch. med. Wschr., 59, 2553.

Stuart, H. C. (1923). Amer. J. Dis. Child., 25, 135.

Svedberg, T., Carpenter, L. M., and Carpenter, D. C. (1930). J. Amer. chem. Soc., 52, 701. - (1931). Ibid., 53, 1812.

Tugendreich, G. (1911). Berl. klin. Wschr., 48, 224.

Umikoff, N. (1896). Jhrb. Kinderheilk., 42, 356.

Urbach, H. (1938). Klin. Wschr., 17, 633.

Zimmermann, M. (1928). Z. Kinderheilk., 45, 310. 